\title{
EL REGIMEN ADMINISTRATIVO SEGUN POSADA HERRERA
}

Creo que sean necesarias unas palabras preliminares para dar a conocer la figura científica de don José Posada Herrera. Nacido en I 8I 4 en Llanes, recibe la primera instrucción cerca de su pueblo, en Celorio, y la enseñanza superior en Oviedo y también en Toledo, cerca del Cardenal Inguanzo, y así se forma una figura interesante en la vida política y científica de España. Posada Herrera fué también matemático, político y jurista. Como matemático explicó en la Universidad de Oviedo la cátedra de Matemáticas, cuando había organizado este estudio en la Universidad en colaboración con la Sociedad de Amigos del País.

Como político representó diversos pueblos, además de su pueblo natal, otros de Asturias, León y Santander, durante treinta y cinco años, en el Congreso de los Diputados, habiendo figurado también como constituyente en las Cortes representando la circunscripción de Oviedo en I869. En este año se destacó ya Posada Herrera. Fué secretario del Congreso en I843, vicepresidente en I 853 y presidente en I 87 I y I88I. Además fué colaborador con el ministro Moyano en la famosa ley de Instrucción pública, casi centenaria, ya que todavía en parte está vigente, en lo no derogado por la ley de ordenación de la Universidad española. Me refiero a la ley de 9 de septiembre de 1857. Figuró como Ministro de la Gobernación con Isturiz, con el General O'Donnell, interinó el de Gracia y Justicia y Fomento en 1866, representó en I869 como Embajador a España en Roma y culminó su carrera política en la Presidencia del Consejo de Ministros en I883, en una edad madura y tras de una experiencia política de la que tan en desuso estamos al día y que no es desdeñable en la vida pública para gobernar.

224 Fué además un gran jurista y hombre de ciencia, pues de otra 
suerte no hubiera alcanzado la Medalla de número de la Academia de Ciencias Morales y Politicas, de Correspondiente de la Española, de Presidente del Ateneo y de la Academia de Jurisprudencia. Publicó principalmente el tratado denominado "Lecciones de administración". Tiene multitud de trabajos inéditos, discursos políticos, también artículos sobre lo contencioso administrativc en "La Revista de España y del Extranjero". Es, pues, esta tercera faceta de la personalidad científica de Posada Herrera la que más nos interesa, o sea el-jurista. $Y$, además, jurista que vivió la vida del Derecho, porque ocupó la Fiscalía y la Presidencia del Consejo de Estado. Culmina esta obra en las "Lecciones de administración". Fueron expuestas en la Escuela de Administración, que se fundó por Decreto de 29 de diciembre de I842, para la formación de funcionarios del Ministerio de la Gobernación. Algo así como es hoy este Instituto de Estudios de Administración Local para los altos cargos directivos de las Corporaciones locales. Se exigían entonces dos cursos, a fin de poder desempeñar esos cargos de funcionarios del Ministerio de la Gobernación. Se tenía, pues, ya un concepto del carácter técnico de la función administrativa que se requiere para el desempeño del ejercicio de dichos cargos.

Publicáronse tres tomos, los cuales fueron tomados taquigráficamente por taquígrafos del Senado, y el último tomo, el cuarto, fué redactado por el propio Posada Herrera, constituyendo uri estudio sobre la Beneficencia pública, con referencias históricas, doctrinales y jurídicas, donde desarrolló magníficas ideas de política benéfica y en la que recoge las de publicistas españoles, como Luis Vives, Giginta, Medina y otros.

Ahora vamos a ver cómo ha penetrado la ideología jurídicoadministrativa y la práctica y la realidad jurídico-administrativa francesa en nuestro autor, conservando, sin embargo, éstós una cierta independencia, como hacía observar ya el maestro Gascón y Marín.

Surge el régimen administrativo a fines del siglo XVIII o principios del XIX en el continente. En época anterior, con el fetichismo de la ley como expresión única de la voluntad del Príncipe, con la glorificación de éste y con la concentración en sus manos de todos los poderes, éstos se confunden, si bien fija la vista en el bien de los pueblos. Sin embargo, algunas diferencias van surgiendo, pues aparecen órganos delegados del Poder eje- 225 
cutivo. Por otra parte, las funciones administrativas eran escasas, apenas si existían servicios públicos. Cuando se empiezan a iniciar éstos, se precisa coordinar la función y el imperio del poder con los derechos preexistentes de los individuos. Así como en un régimen político liberal se pueden ejercer todos los derechos que no estén taxativamente prohibidos por la ley y pueden escribirse libremente las ideas propias sin censura previa, en un régimen político de policía no pueden ejercerse derechos que no estén permitidos por especiales autorizaciones. Pues bien, en el régimen administrativo puede darse una dualidad semejante, si bien fijando las ideas en la Administración, no en el individuo. En un régimen administrativo pueden municipalizarse todos los servicios generales que no estén taxativamente prohibidos por la ley, y en cambio en regímenes no administrativos, es necesario que la ley los autorice expresamente. Así sucede en los Fstados sajones y otros en el continente.

Las características del régimen administrativo del continente que surge en Francia, es-os lo decía aquí también Gascón y Marín-la doctrina de la separación de poderes. Veamos sintéticamente cómo evoluciona esta doctrina o, mejor dicho, cómo se plasma en la realidad, como se entiende.

Una ley francesa de 16 de agosto de 1789 , prohibe que los Tribunales realicen funciones administrativas, pero no que enjuicien a la Administración; otra de I3 de septiembre del 9r, tampoco prohibe que los Tribunales no puedan juzgar a la Administración. Es la ley de 16 Fructidor del año III, en la que se prohibe terminantemente que los Tribunales conozcan de los actos de la Administración, cualesquiera que sean éstos. El Poder judicial, no sólo puede realizar funciones administrativas, sino que tampoco puede juzgar a la Administración. Se confundían los órganos de poder con la función de que hacía mérito anteriormente aquí nuestro querido maestro Gascón y Marín. Entendieron, pues, los constituyentes franceses que la Administración no puede ser juzgada por la autoridad judicial en un régimen administrativo. La Administración sí ciertamente debe estar sometida a la ley, pero al no discernir que el poder judicial debe ser quien juzgue a la Administración, no quien administre, confundieron la acción administrativa con la judicial. Es evidente que los Tribunales ordinarios, con arreglo a esta doctrina, no deben 226 realizar funciones administrativas para evitar cualquier tiranía; 
no comprendemos por qué no pueden ejercer sus propias funciones, tanto da que se juzgue a los particulares como que se juzgue a la Administración. Es un problema de lógica jurídica. Es la ley intangible; si la ley se ha infringido, la Administración debe cumplirla y alguien debe decirle a la Administración que cumpla esa ley. El régimen administrativo se concentra y se recoge en el 28 Pluvioso del año VIII, que afirma de una parte una poderosa centralización administrativa, de otra, aquella misma doctrina, ya que los constituyentes de la Revolución francesa excluven del Poder judicial el juzgar los derechos administrativos, al mismo tiempo que requieren la necesidad de la autorizarión administrativa para procesar a los funcionarios, doctrina emanada de la responsabilidad de la Administración en sus actos de poder público, que se consideran como algo inherente al régimen administrativo, es una doctrina jurisprudencial que va a iniciarse muchos años después.

Se recibe la doctrina de separación de poderes en España, por los legisladores de las Cortes de Cádiz, que la incorporan a la Constitución del I2, la cual marca el límite en que debe encerrarse el Poder judicial. Se recoge también en el artículo 63 de la ley del 37, que dice que a los Tribunales corresponde exclusivamente la potestad de aplicar las leyes en los juicios civiles y criminales, no pudiendo hacer otra función que juzgar $\mathrm{y}$ hacer que se ejecute lo juzgado. Incurren en la misma errónea interpretación que los políticos franceses. Creían que la Administración no puede ser objeto de enjuiciamiento. Atribuían al Poder judicial competencia para entender en las cuestiones civiles, pero no en las administrativas. Esta doctrina va a tener su desarrollo en la legislación. Se intenta implantar en España la jurisdicción contencioso-administrativa en el año 38 , con la institución de unos Tribunales a imitación de los del Consejo de Prefectura franceses, denominados Consejos provinciales, iniciativa de Don Luis Silvela, y al mismo tiempo una Comisión integrada por varias per'sonalidades presenta al Ministro un proyecto referente a la creación del Consejo de Estado, de suerte que este órgano queda más bien incorporado al Poder ejecutivo, para entender, no sólo en cuestiones gubernativas y administrativas, sino en los problemas jurisdiccionales concernientes a las situaciones del Derecho administrativo. Este inflưjo francés se ejerce también en Posada Herrera con determinadas reservas, porque él mismo dị- 227 
ce que, a pesar de reconocer que Francia tiene para nosotros un modelo en materia de instituciones administrativas, como en materia de instituciones políticas, no cree que se deben abandonar nuestros usos y costumbres españolas, sin perjuicio, naturalmente, de que no se deban rechazar todos los principios luminosos y claros del extranjero, que nos puedan servir, sean de procedencia de países amigos o enemigos, con tal de que sirvan a las reglas de nuestras instituciones políticas en muchos casos.

Sus ideas a veces resultan contradictorias, porque pugnaban las ideas originales y personales y propias, con la influencia fran'cesa, pues, pensando en una Administración legal parece como que a su juicio deben ser ciertamente contenidas en límites legales, pero por el propio Poder judicial atento a garantizar los derechos individuales, y otras veces, más quizá que por razonamientos políticos franceses, por otro orden de cosas, no acepta la sumisión del Poder administrativo, como llama Posada Herrera a la Administración-yo creo que con excelente criterio, para no confundirlo con el Gobierno o el poder gubernativo o poder moderado- No acepta, digo, la sumisión del Poder administrativo al Poder judicial.

Sin perjuicio de que desarrollemos ésto un poco más adelante, expongamos una idea núcleo interesante sobre lo que entiende por centralización y descentralización, también decía excertralizada, al igual en "El Tratado de Administración", con relación a España que Oliván, no quiere ésto decir que entonces no pudiera utilizarse el prefijo des, porque precisamente Valdés, en el "Diálogo de la L.engua"; expone como el prefijo des es todo lo contrario de lo que significa la palabra siguiente: "hace que el vocablo con quien se junta muda la significación de bien en mal"; de modo que puede utilizarse perfectamente bien la palabra desicentralización.

En esto se siente propio, el político jurista asturiano, criginal con arreglo a sus usos y costumbres. Acepta, pues, la centralización política, pero no la administrativa. Compete al Gobierno, al Estado, ejecutar y disponer que todas las fuerzas que hay en el Poder estén prontas a su mandato, a fin de que puedan ser tenidas y defender la nación de los ataques interiores y exteriores, que debe poder recaudar las rentas públicas, sin-que encuentre el menor obstáculo en su recaudación, que debe llamar a los hom228 bres, hacer la recluta sin establecimiento de fueros, subsistir, 
entonces, las excepciones de las quintas en Vasconia, pero en cambio, lo que no admite es la centralización administrativa. Para disponer de los bienes, para administrar la fortuna de los pueblos, basta con que se reserve cierto veto por parte de la Administración central para que no se dilapide la fortuna de éstos, y denuncia el hecho de la burocracia, que retarda la marcha administrativa de los asuntos. Hoy observamos que no consiste este defecto burocrático en el mayor o menor número de funcionarios, sino en una buena distribución de éstos y de sus jefes, en que no exista esa elefantiásica formación central que todo lo absorbe e impide ciertas iniciativas y desarrollos locales, y así decía Posada Herrera que no debían venir a la capital los expedientes pequeños que no importan a los intereses generales, porque no podían resolverse con acierto, porque además retrasan toda la marcha administrativa. $\mathrm{Y}$ aquí, pues, seguramente estáis hoy funcionarios administrativos escuchándome, sabéis perfectamente bien lo que hace retardar su solución, el ir al centro una serie de expedientes por nimiedades, como la enajenación de una parcela.

Resume Posada Herrera, sus ideas de la coordinación del régimen administrativo regional con el local, diciendo Gobierno central, Administración central, para todos los intereses generales del país, Administración local confiada a los Ayuntamientos y Diputaciones provinciales en toda la latitud que sea compatible, así con el Gobierno de la nación como con la Administración general.

$\mathrm{Y}$ ahora voy a otro tema-al iniciado ya con carácter general--y a exponerle muy rápidamente porque no quiero cansaros. Volviendo sobre aspectos que he venido tratando: me refiero al problema del enjuiciamiento de la Administración. Para él hay unas razones de técnica y oportunidad por lo que no debe la Administración ser enjuiciada por el Poder judicial. El Poder judicial, sin los datos que la Administración tiene a la vista, sin los medios para enterarse de los hechos y conocer las necesidades de la sociedad, no puede fallar sobre estas necesidades mismas y resolver todas las dificultades. Claro está que para ésto-y aparte mi criterio-lo único que hay que hacer es sustituir los Magistrados que tengan una deficiente formación administrativa, con Magistrados que la tengan completa. En ésto, sin embargo, se observa la influencia en Posada del prejuicio francés, del prejuicio político, de que el Poder judicial está más dispuesto a aten- 229 
der los intereses individuales y a reconocer los derechos, que a atender los intereses generales y comunes. No aboga, sin embargo, porque el órgano jurisdiccional sea un órgano administrativo activo, ni las Diputaciones, ni los Ayuntamientos, ni los propios Ministerios, ni órganos tan distintos y variados, como está sucediendo hoy en Inglaterra, en que surge un órgano para cada materia, sino un organismo que entienda de todos los asuntos contenciosos, aparte de aquéllos de carácter consultivo de la administración superior. Pensaba, sin duda, en el Consejo de Estado, que no debe suspender los actos de la Administración.

La suspensión de la ejecutoriedad de los actos y las decisiones administrativas, es uno de los inconvenientes que imputa Posada Herrera a los Tribunales ordinarios, par'a enjuiciar aquéllos, porque no quedarían salvaguardados los intereses comunes, los intereses públicos.

En casos de inundación, de guerra, etc., no pueden suspenderse las decisiones administrativas por los Tribunales, aunque se atenten derechos de propiedad. Surgirá entonces el problema de que nos hablaba también el señor Gascón, el de la responsabilidad de la Administración, sobre el que no nos han descubierto nada nuevo fuera de aquí, pues Posada Herrera opinaha ya ante este estado de cosas que era necesario utilizar o destruir la propiedad o un objeto sin suspender la resolución administrativa. No puede pararse la Administración ante ésto, ante ciertos obstáculos, los Tribunales, ni la propia Administración. A su tiempo, la persona agraviada-dice-- tendrá donde reclamar sus derechos, donde hacerlos valer. Las leyes deberán proveer en éste y en otros casos, para que el individuo no sea sacrificado al interés de la sociedad, sin la recompensa o la indemnización a que es acreedor. Ahí tenéis la doctrina de la responsabilidad de la Administración. $\mathrm{Y}$ aún hay otros textos más que hablan sobre ésto, por ejemplo en la página 25 I del tomo I de las "Lecciones de Administración", se dice que si bien es lícito obligar al particılar a que renuncie a sus derechos privados en beneficio del procomún, también "ese particular tiene derecho a que estas usurpaciones se legitimen, y se le resarza del modo que sea posible".

Discierne perfectamente nuestro biografiado, bien lo que ha de ser la materia contencioso-administrativa y hasta si se quiere no con un método enumerativo, sino de enunciación declarativo, 230 de cláusula general. Distingue, pues, el autor, con referencia a 
la naturaleza de la ley que trata de aplicar, materia derivada de leyes administrativas de las emanadas de las leyes políticas, materias jurisdiccionales de las que no lo son, y en general las resoluciones administrativas de las que afectan a los grandes asuntos nacionales, cuyas últimas no deben ser objeto de recurso contencioso-administrativo. Cita el caso de la prohibición de la exportación del trigo, que se haya dado por la Administración y que no es ni siquiera una ley de carácter material, es una medida administrativa general, quizá tenga algo de tipo político, aunque de carácter económico.

Cita una tercera categoría de actos de la Administración, tampoco controlables por la vía contencioso-administrativa, sin duda se refiere a lo civil, aun cuando existen determinadas intervenciones administrativas, como en la relativa a la propieda 4 intelectual o licencias de construcción, pongamos por caso. Los problemas que se ventilan entonces entre las partes son de índole civil, controlables ante los Tribunales ordinarios.

Pero no sólo por exclusión llega Posada Herrera a la formación del concepto general de la materia contencioso-administrativa, cuando dice que ésta abraza todos aquellos asuntos contencioso-administrativos en que un particular entra en litigio con la sociedad sobre materia administrativa: habría que definir, sin embargo, qué es materia administrativa. Comprende también entre la materia contenciosa todas las que han nacido de queja promovida contra algún empleado por exceso de poder o abuso de las atribuciones que la ley concede. Todavía ciñe más este concepto, por lo menos en lo que se refiere al contrato administrativo, al apuntar la acción de oficio para la anulabilidad, la modificabilidad o la suspensión de sus efectos, cuando el servicio común, la razón pública o la necesidad lo réquiriesen, sin la intervención de los Tribunales, puesto que el servicio público no puede ponerse a su merced. A posteriori puede impugnarse el acto administrativo ante los Tribunales, en los siguientes casos que enumera en el artículo sobre lo contencioso-administrativo en la Revista de España y del Extranjero.

I.- Que la materia de que se trate y las leyes y principios que se hayan de aplicar, pertenezcan al orden administrativo.

2. Q Que la cuestión debe verse sobre revisión o modificación de un acto administrativo que ataca derechos preexistentes.

3. ${ }^{-}$Que este acto no tenga carácter constitucional o político 
ni de reglamento o disposición general en favor de intereses públicos.

4. Q Que no esté comprendido en concesiones graciosas que el Gobierno tiene facultad de hacer con arreglo a leyes.

5. - Que tampoco lo esté en aquellas resoluciones de parecer o consejo o aquellos actos de simple tutela administrativa que dejen indemne el Derecho de los particulares.

6.. Que no haya lugar a otro recurso judicial ni administrativo.

En una palabra, no son impugnables los actos de gobierno, los actos discrecionales y los actos reglamentarios y los actos para los cuales exista ya una jurisdicción especial. Distancia la jurisdicción ordinaria cuando la Administración obra como Poder público, al referirse a los asuntos municipales, y determina cómo sí puede actuar el Municipio en calidad de persona jurídica particular en el arriendo de bienes propios; - en la venta o celebración de cualquier género de contratos sobre está materia, es decir cuando actúa como persona privada, lo cual es materia siempre jurisdiccionable en la vía ordinaria; en cambio, cuando se trata de construcción de obras públicas, de abusos de empleados considera más propiamente actividad administrativa, y sus litigios se resuelven ante los Tribunales administrativos.

Para sujetarme al tiempo que se me ha fijado pasaremos por alto la crítica que hace Posada Herrera de la omisión de procedimientos observada en los Consejos de Prefectura franceses, Para no cansaros también, dejo de exponer su punto de vista sobre la autorización previa gubernativa para juzgar a los funcionarios de la Administración, ya que aquí no hay en e! autor ninguna originalidad. Sigue el criterio francés, adoptado en la ley de 14 de diciembre de I789; 24 de agosto de 1790 , en el artículo 75 de la Constitución del año VIII, autorización previa exigible en España por la ley de 2 de abril de I845, el R. D. de 27 de marzo de 1850 , la ley de 28 de septiembre de 1866 , suprimida en la Constitución de 1869 , y dispuesto se restableciese por ley, en el artículo 77 de la Constitución de 1876 , ley que no fué promulgada (I).

(1) Véase lo que sobre este particular figura en el artículo 666 de la ley de En232 juiciamiento criminal y en el tercero del R. D. de 8 de septiembre de 1887. 


\section{Y voy a terminar:}

En su trabajo sobre lo contencioso-administrativo alaba Posada Herrera el que el Poder administrativo y el judicial no estén confundidos y el que en los Gobiernos constitucionales imponga el Rey la obligación de delegar en jueces inamovibles la posibilidad de aplicar las leyes civiles y criminales.

Pero no estaban los abusos del llamado Poder ejecutivo en dirimir las contiendas entre particulares, sino también entre la Administración y el particular, al socaire o ante las invocaciones del interés público, es decir en convertirse en juez y parte.

En dicho artículo en cuestión, se insiste en retirar el enjuiciamiento de la Administración a los jueces ordinarios, y se basa -más que en las "Lecciones de la Administración"-, en el problema político, para nosotros equivocado, de la separación de Poderes, que lo están, separadas que fuesen o que sean las funciones, ya que objetivamente siendo actividades distintas, pueden estar en órganos distintos, y así lo será el administrativo del judicial cualesquiera que seâ el negocio jurídico que juzguen el último llevado a cabo entre particulares, entre Administraciones públicas o entre aquéllos y éstas.

Esta preocupación política que no es sino consecuencia del influjo francés que sobre Posada Herrera ejerce, aunque no tanto como en Silvela, se observa cuando dice que la jurisdicción de los Tribunales no invade la de la Administración para resolver las dificultades que se opongan a la ejecución de las leyes, ni menos para interpretar sus propios actos aunque su conocimiento e interpretación haya de resolver sobre los derechos de los particulares y si otro fuera el sistema-añade-que se adoptase, llevando tales asuntos el fallo de los Tribunales ordinarios, "haríamos a éstos superiores a la Administración contra el espíritu de nuestra ley política que deslinda las atribuciones del Poder judicial y Administrativo".

Como objeción a estos prejuicios de Posada Herrera, manifestaremos que no'sería el juez el superior, sino la ley que infringiese el Poder adminstrativo, sin que por eso creyésemos tampoco que el Poder legislativo sería superior al judicial, porque aquél no podría dejar sin efecto una sentencia ajustada a la ley o un acto administrativo ajustado a Derecho, mientras este derecho fundamental no fuese previamente derogado, para lo cual un Poder de garantías constitucionales o un Poder tra- 233: 
dicional y moderador, el Monarca, el Jefe de Estado, al ejecutar funciones políticas, distintas no superiores a las legislativas, judiciales y administrativas, con derecho de sanción o de veto, negaría aquélla o opondría éste, para impedir el incumplimiento o la vulneración de una ley constitucional del Derecho normativo, de una ley tradicional, básica, o costumbre consagrada por el tiempo inveterado como norma fundamental del país.

Así concebiría yo un régimen jurídico-administrativo y político en momentos en que se haya de normalizar la vida pública española, en relación con la normalidad del mundo, por lo menos europeo.

$Y$ ya es cosa que vayamos peńsando en el cauce jurídico del nuevo orden estatal, y sin duda al recordar a los administrativistas de hace un siglo en un período que podríamos calificar de despotismo ilustrado, creo eso es el propósito del ilustre iniciador de estas veladas científicas, del maestro Gascón y Marín, que con Posada y Royo Villanova, representan un enlace entre el régimen liberal y el autoritario, lo cual no quiere decir antijuridico, pues de lo que se trata es de que se respete la ley del Candillo o de las Cortes y el Caudillo por gobernantes y administradores, por Ministros y Subsecretarios, por Directores Generales y autoridades delegadas del Poder central en provincias; en suma, que se respete al nuevo ordenamiento jurídico, y para ello no hay otro modo de lograrlo que restableciendo-con las modificaciones que aconsejen las circunstancias presentes-la jurisdicción contencioso-administrativa.

Sabino Alvarez Gendin. 